\title{
The Collaborative Economy Based Analysis of Demand: Study of Airbnb Case in Spain and Portugal
}

\section{Pedro R. Palos-Sanchez ${ }^{1}$ and Marisol B. Correia ${ }^{2}$}

\author{
${ }^{1}$ International University of La Rioja, Department of Business Organization and Marketing, Logroño, Spain \\ pedro.palos@unir.net \\ 2 University of the Algarve, School of Management, Hospitality and Tourism, Faro, Portugal \\ Centro de Investigação, Desenvolvimento e Inovação em Turismo (CiTUR), Portugal \\ University of Lisbon, Centro de Estudos de Gestão do Instituto Superior Técnico (CEG-IST), Lisbon, Portugal \\ mcorreia@ualg.pt
}

Abs Received 8 June 2017; received in revised form 24 September 2017; accepted 27 December 2017

\begin{abstract}
The rise of the collaborative economy has just started to become a reality in the economy of the countries in the European Union. The aim of this article is to use Goal - Question - Metric methodology to verify that the rise of Internet searches has an impact on collaborative economy. Specifically, Airbnb was the collaborative economy service analyzed. The demonstration was carried out with a statistical analysis of the Internet searches, looking at their evolution in Spain, Portugal and USA over the past 10 years. A working hypothesis was also defined to test whether the demand for information about Airbnb has a positive influence on the total spending of tourists who booked apartments in Spain during the period between July 2015 and August 2016. The results lead us to make a projection of growth for Airbnb service in the coming years. The case studied is very representative of this economic model, even though there is a large number of lesser-known websites. Finally, the results corroborate previous studies that defend that tools for studying trends and correlations of search terms are techniques that help decision making in studies and market research.
\end{abstract}

Keywords: Sharing economy, Google Trends, Collaborative consumption, Airbnb, Cloud computing 


\section{Introduction}

In the coming years, there will probably not be any productive sector that does not have to deal with technological innovations. Many of them will have to adopt these innovations to adapt to the environment, but will be more and more affected, to a greater or lesser extent by the so-called digital economy. Especially, since the advent of the phenomena of digitization of information and the emergence of Internet, the so-called digital economy has emerged.

This new economy has staged a new revolution based on networked human intelligence. However, its appearance has not only brought numerous promises and unlimited opportunities for wealth creation and social development, but also involves potential danger for those individuals, companies and firms who lag behind [60].

For this author, one of the main differences of the digital economy and that which makes it different from the traditional economy is disintermediation, i.e. the disappearance of many intermediaries because consumers and producers can communicate directly and easily. However, the other difference to note, which is fully applicable to the subject of this article, is the prosumer. This term incorporates the words provider and consumer and defines the disappearance of the gap between consumers and suppliers. Consumers have a greater influence on the production process, which means that procedures should be established to learn more about the needs and tastes of customers [61].

In response to these two differences, which among many others clearly distinguish the digital economy from the traditional one, we must ask whether the statements of [60] are in full force when we read in the media news related to disputes that are being caused by the production of passenger services, such as Blablacar, Uber, Cabify or Drivy, among others. It is hard to know if we are dealing with transport companies, travel agencies, car rental agencies or taxis because the traditional economic model does not contemplate disintermediation and prosumption.

The traditional economy is based on a network of vertical type organizations. Vertical organizations are defined as those that provide society with goods and services to consumers who purchase their possession and/or Rights of Use. Informal practices are those that create value in a purely horizontal manner. This means that a consumer can help another without monetary profit or can exchange goods for services or other goods. The current phenomenon of collaborative economy lies in creating a hybrid model out of these two; that model in which the vertical and horizontal organizations act together. This is what is known as a diagonal adaptation of both models [12].

A new economic model that favours collaboration between consumer and producer is created, primarily using technology and in which a reciprocal relationship with the objectives of each party is maintained. These two features should be observed simultaneously, because each party must contribute to this relationship, either with knowledge, money, services or other items.

One of the technologies that has contributed the most to the collaborative economy has been cloud computing. This technology represents a paradigm change in business because it is no longer necessary to have hardware and software servers at the offices of the company and the processes are performed accessing the Internet [48]-[49]. Most companies that base their collaborative economy model on the potential of the Internet, use cloud computing as support and architecture. This is because this technology offers a scalable market-oriented architecture [14]; the potential to transform business processes [45]; its potential to provide better knowledge management and a closer link between information systems and management requirements [56] and even its ability to offer competitive advantages, given the reductions in capital and the operational and maintenance costs related to Information Technology (IT) that allow the reorientation of resources towards fundamental commercial activities [50].

The aim of this article is to demonstrate, using the GQM (Goal - Question - Metric) methodology and studying the increasing demand for information, that the rise of Internet searches has an impact on collaborative economy. The collaborative economy service studied was Airbnb and the demonstration was carried out with a statistical analysis of the Internet searches of the brand analyzed, studying its evolution in Spain, Portugal and the United States over the past 10 years. Similarly, a comparison of these searches has been made with web searches for tourist services on the Internet, since the tourist sector is being transformed by the collaborative economy, especially in the change of accommodation model that has the new alternative of tourist apartment booked by Internet. A hypothesis was defined to verify if the demand for information about Airbnb has a positive influence on the total spending of tourists who booked holidays apartments in Spain during the period between July 2015 and August 2016. Finally, we checked the correlation that can be found with the increasing demand for information about social networks and Internet access providers. These findings lead us to make a projection of growth for this service in the coming year.

To achieve this goal, the article is divided into four parts. Section 2 presents a review of the literature on the economy and collaborative consumption and the use of collaborative economy services in the tourism sector. Section 3 presents the methodology, in particular the analysis tools for search words, the capacity for prediction of the search statistics in Google, the GQM methodology, the case study of Airbnb and the hypothesis formulated. To obtain the data, two search word analysis tools have been used, Google Trends and Google Insights for Search, which assess the prominence and demand for a set of search terms on the Internet using the Google search engine. This has been done with a quantitative method of observation and analysis of the words or search phrases entered into search engines by users, 
using Google Trends and Google Insights for Search. Next, section 4 shows the analysis of the results obtained, structured using the GQM model. Finally, the conclusions and the implications for the future, obtained from the results of this study, are presented.

\section{Conceptual Background}

The Conceptual Background section presents the definition of the Collaborative Economics. In this section the main definitions and the evolution of this concept are shown. In a second section titled Tourism and the Collaborative Economy, the relationship of this economy with tourism and its main implications for research is presented.

\subsection{The Definition of the Market: Collaborative Economics}

The redefinition of the relationships within markets is conditioned by a change in the roles between sellers and buyers, by the expansion of the models of transaction and consumption and by how all this affects the business models and the business and technology ecosystems. In this way, today a market trend is emerging in all exchanges of goods and services between people, replacing the traditional business to consumer economic model. This trend is defined as Collaborative Economics, i.e., as an economic model where ownership and access are shared between companies, startups and consumers. This translates into a market of efficiency, which aims to efficiently offer new products and services [47].

The immediate precedent of this economy is found in collaborative consumption, sometimes called economy of exchange, and the peer-to-peer movement. Collaborative, cultural and economic consumption is the force that is transforming business, consumerism, and the way we live. With the onset of the economic crisis, the collaborative economy boomed and the continued growth of users of these services began [62].

Recent changes in our economic climate, especially the recent crisis, have intensified this phenomenon. Businesses and organizations are redefining the way goods and services are valued and exchanged. The concept of collaborative consumption became popular with the publication of the book What's Mine Is Yours: The Rise of Collaborative Consumption [13]. This new phenomenon started to be detected in various sectors, but those with exceptional growth are the financial, tourism and technological sectors. Collaborative consumption is defined as: The use of marketplaces or online web stores and social networks for easier peer-to-peer interchanges, i.e. to share resources (e.g, space, money, goods, skills or services) among individuals who play both the role of providers and consumers [10].

Collaborative consumption is developed under three systems [13]:

- $\quad$ Product-service systems, where the consumer pays for, but does not acquire the property;

- Redistribution markets, where the transfer or exchange of used goods occurs;

- Collaborative life styles where people who share interests and a common philosophy of life connect to share and exchange intangible resources such as time, space, skills, and money [19].

Collaborative consumption is part of a larger pattern: the collaborative economy. This is a model of economic exchange that is based on three fundamental principles: interaction between producers and consumers who maintain a continuous dialogue, peer connection thanks to different technologies especially digital, and collaboration [63].

In this new mode of consumption, the concept of renting or sharing is changed for a more intelligent, humane and efficient way of consuming. This does not mean that users do not buy anything, just that they do not have to buy everything. Initiatives based on the collaborative model as a whole are changing the cultural concept of the possession of objects or consumption of services. This creates collaborative consumption practices, which are becoming everyday actions for consumers. This model includes various processes, such as the production (crowdsourcing, collective innovation, open software, coworking, user-generated content), financing (crowdfunding) or consumption.

Prior to the appearance of collaborative economy and especially before the birth of the Internet and Web 2.0 technology, the exchange of goods was limited to the geographical area closest to the consumer. There would not be a collaborative economy, as we know it without the emergence of Web 2.0 technology. Hence, it is the result of taking and using the Internet culture created over the past fifteen years, outside the digital environment [15].

The collaborative economy can be classified into four segments: collaborative consumption, contributory production, peer-to-peer finance and open knowledge. Collaborative consumption is the most widespread and developed segment of the market. Meanwhile, contributory production illustrates a new industrial model of peer-to-peer production, based on the maker's movement, the Do-It-Yourself (DIY) culture and the application of open software methodology principles to manufacturing.

The combination of these principles results in the beginning of a new industrial revolution that democratizes physical 
production, just as blogs and social networks have democratized publishing content [4].

In the near future, other models will be in greater demand, such as equity crowdfunding or peer-to-peer lending. Finally, we must say that the open knowledge segment allows for rapid growth and distribution of the different models [7].

\subsection{Tourism and the Collaborative Economy}

Thanks to the Web 2.0 technologies, we can access goods and services worldwide. The concept of sharing economy [1] was coined in Spain under the term collaborative economy, which begins to be mentioned in 2012, especially in the tourism sector [22]. Nowadays, consumers make plans using the Internet as a source of information to make bookings and to contrast opinions. The clear influence of using technology as a means of planning also reveals tastes, trends and demands. Especially through the analysis of search words in two dimensions: geographical space and time.

Consumers plan their trips. For this, they need to make many decisions such as destination selection, accommodation, transportation, activities, restaurants or other [31]. Thus, travelers will try to obtain relevant information in the Internet search engine, by using keywords related to tourism and, therefore, to search for keywords related to the different stages of the trip [51]. Tour operators and, in general, all companies involved in promoting a destination, know the importance of these analyses. As we have already said, one of the areas that has shown most interest in the collaborative economy has been tourism.

In the international tourism industry, it is very important to forecast the influx of foreign tourists accurately and promptly. Getting accurate and short-term forecasts of tourism demand is very important because tourism assets, such as airline seats, restaurant tables or hotel rooms are not storable [5], [35]-[36], [51].

Data on the number of searches done on Google obtained by the Google Trends tool shows information in nearly realtime on trends and allows the investigation of collective behavior, which have been used as indicators of public opinion in the real world [70].

Investigations in Tourism has been developing new models of tourism demand prediction using Internet search data, such as using Google Trends data to estimate the tourist demand of five tourist destinations in the Caribbean [9], forecast the number of tourists in Hainan Province in China with Google and Baidu [68] or, recently, forecast the number of Japanese tourists visiting South Korea [51].

\section{Methodology}

The Methodology is structured in seven sections. First, the main analysis tools for search words are exposed. Second, the theoretical foundation that supports the capacity for prediction of the search statistics in Google is presented. Subsequently, the specific methodology applied to the case study is exposed: the GQM Analysis Method (Goal Question - Metric), the case study and the hypotheses to be tested. Finally, the data and sample characteristics are presented.

\subsection{Analysis Tools for Search Words}

To assess the familiarity and demand we chose a quantitative method of observation and analysis of the words or phrases entered by users in search engines. The two analysis tools used were: Google Trends and Google Insights for Search. Google Insights for Search is a more sophisticated and advanced service displaying search trends data. On September, 2012, Google merged Google Insights for Search into Google Trends [42], however the data remain accessible to discover correlated terms.

Google Trends is a program that analyzes trends and provides a temporal series of the volume index of the user's queries, which have been put into the Google search engine in a particular geographic area. The index is based on the ratio of total number of queries for the search term in question within a particular geographic region, divided by the total number of queries in that region during the time period examined [17]. This allows the identification of variations in searches with relative values based on a scale of 0 to 100 , where 100 represents the highest level reached in searches performed with respect to a term or keyword.

Google Trends is a tool, recognized in research as a solid and valid indicator for tracking the frequency of occurrence of certain terms that could hypothetically function as catalysts of interest, attention and presence in the public opinion of an item [24].

Google Trends is suitable for analyzing social behavior or potential seasonality for other information [54]. Other economic research has been in share indices [25], where demand is explained by the mood of investors, which is found by analyzing statistics from Google searches for certain terms relating to financial markets.

Graphically the result is shown with temporal limits from 2004 to the present and with the vertical axis representing the frequency with which the term has been searched for. 


\subsection{Capacity for Prediction of the Search Statistics in Google}

Some authors have demonstrated the predictive ability of some research techniques, such as surveys of consumer confidence [34]. Now, technological developments and especially the emergence of search engines and their complementary tools, like Google Trends or Google Insights, have changed consumer habits. Many of them, before consuming a service or product, consult the Internet. Thus, knowing and viewing the keywords, which consumers seek on the Internet, is a predictive tool on future demand for a product or service.

Knowledge of search term statistics in Internet offered by these tools for free has certain advantages over surveys, because of ease of data collection through a tool rather than having to arrange for an online sample size equivalent to the data returned from online search statistics. Another reason is that they can be obtained directly in electronic form, and can then be easily treated, they are customizable by category, period and even geographical area, and barely have any time lag, as they are available on-line [39].

The predictive ability of the statistical study of search terms has been demonstrated in many investigations. Table 1 shows the main studies published in leading journals, which use Google Trends in the field of Business and Management. It must also be noted that this tool has been used in research to quantify trends of public interest in keywords for different works and studies.

In the field of economy we have found various studies such as those that predict economic indicators: car sales, unemployment or tourist destinations [16]-[17], business information [64]-[65], applied economics [16] [53], human resources [7], [18], price developments [27], consumption [28], [37] [52], [54] [58] and digital economy [32]-[33].

Table 1 presents a series of similar investigations. The research work developed in this paper also addresses a study within the tourism sector, but it does so from the perspective of a collaborative economy service related to accommodation in shared tourist apartments.

Table 1: Similar studies that use google trends in tourism

\begin{tabular}{|l|l|l|}
\hline Literature & Title & Reference \\
\hline $\begin{array}{l}\text { Artola, C., Pinto, F., \& de } \\
\text { Pedraza García, P. (2015) }\end{array}$ & $\begin{array}{l}\text { Can Internet searches forecast tourism } \\
\text { inflows? }\end{array}$ & {$[6]$} \\
\hline $\begin{array}{l}\text { Bangwayo-Skeete, P. F., \& } \\
\text { Skeete, R. W. (2015) }\end{array}$ & $\begin{array}{l}\text { Can Google data improve the forecasting } \\
\text { performance of tourist arrivals? Mixed-data } \\
\text { sampling approach. }\end{array}$ & {$[9]$} \\
\hline $\begin{array}{l}\text { Jackman, M., \& Naitram, S. } \\
(2015)\end{array}$ & $\begin{array}{l}\text { Research note: Nowcasting tourist arrivals in } \\
\text { Barbados-just Google it!. }\end{array}$ & {$[30]$} \\
\hline Önder, I., \& Gunter, U. (2016) & $\begin{array}{l}\text { Forecasting tourism demand with Google } \\
\text { Trends for a major European city destination. }\end{array}$ & {$[46]$} \\
\hline Rivera, R. (2016) & $\begin{array}{l}\text { A dynamic linear model to forecast hotel } \\
\text { registrations in Puerto Rico using Google } \\
\text { Trends data. }\end{array}$ & {$[57]$} \\
\hline Vosen, S., \& Schmidt, T. (2011) & $\begin{array}{l}\text { Forecasting private consumption: Survey- } \\
\text { based indicators vs. Google Trends. }\end{array}$ & {$[66]$} \\
\hline $\begin{array}{l}\text { Yang, X., Pan, B., Evans, J. A., } \\
\text { \& Lv, B. (2015) }\end{array}$ & $\begin{array}{l}\text { Forecasting Chinese tourist volume with } \\
\text { search engine data. }\end{array}$ & {$[68]$} \\
\hline
\end{tabular}

\subsection{The GQM Analysis Method (Goal - Question - Metric)}

The Goal / Question / Metric (GQM) paradigm is a mechanism for defining and evaluating a set of operational objectives by taking measurements in a specific project. This methodology represents a systematic approach for establishing the objectives of a project tailored to the specific needs of an organization, defining operatively, and accessible values through the development of a set of quantifiable questions [11].

The GQM model starts with the specification of a goal, followed by the definition of the questions and then metrics for each question are listed. This methodology includes the development of mechanisms for data collection, for example, forms, automated tools, collection and validation of data, analysis and interpretation of the collected data and calculated metrics in the appropriate context of the questions and the original objectives.

A goal is defined by completing a set of values for the various parameters being measured (for what purpose and why), the perspective (what aspect and who), and environmental characteristics (where). According to the GQM methodology, it was considered that the objective of this study is to demonstrate that the data offered by Google Trends and Google Insight for Search provide empirical evidence about the behavior and interests of potential consumers in the 
collaborative economy service Airbnb. For this, the questions that we finally decided should be answered are:

1. What regions and cities show more interest in Airbnb service?

2. What is the interest in the collaborative economy in Spain and Portugal with respect to the country of origin of Airbnb?

3. What is the popularity of the Airbnb service compared with other traditional websites (traditional websites are considered those websites that also offer lodging of hotels and not tourist apartments based on reservations in websites of collaborative economy) like TripAdvisor, Trivago or Booking?

4. Is there a relationship in the rise in popularity of Internet access (fiber, 4G, new operators) and Airbnb service?

5. Is there a relationship in the rise in popularity of social networking and Airbnb service?

In our research, the metrics, i.e., the information to be found in order to answer the questions formulated, were obtained by consulting the Google tools discussed above. However, considering the set of questions, it was necessary to make methodological decisions in order to obtain the desired parameters. Thus, after examining the analysis we decided that the data should be obtained using the comparative analysis provided by the tools.

To answer each of the questions, the appropriate configuration of the application was made. For the first question, the scope was national and discriminates, in turn, between regions and cities. For the second question, the geographical scope was international, the results obtained in Spain, and Portugal were compared with those of United States. The method of study was the comparison of search terms to measure interest in Spain and Portugal and the United States for Airbnb. The numbers reflect the interest in the search term in relation to the highest value of a graph in a region and in a given period. A value of 100 indicates the maximum popularity of a term, while 50 and 0 indicate a popularity that is half or less than $1 \%$, respectively, relative to the highest value [26].

The third question made comparisons with non-collaborative websites and a time span of 10 years was established. The fourth and fifth questions were answered with the Google Trends tool and supplemented with Google Insights.

The aforementioned studies highlight the usefulness of the search terms statistics used in the search engines, and their relevance in the academic environment. Based on this, the objective of our proposal is to demonstrate that such searches are a dependent variable, especially the volume of searches made in Google on certain terms related to the collaborative economy and its most representative brand: Airbnb. Our methodology, in the first place, is based on the explanatory power of Google search statistics. Subsequently, considering macroeconomic data over time we will check if this influences Internet searches for the specific case of the evolution of the collaborative economy.

The data provided by Google Insights is organized by time and by the terms related to the collaborative economy (e.g.: Airbnb). Following other investigations, only those terms for which the searches were maximum or minimum at the time of some relevant economic event, have been considered for this study [39]

\subsection{Case Study}

To carry out a study of the familiarity with and demand for the selected brands and organizations of collaborative economy, a case study methodology applied to tourism has been proposed.

The technique that has been used for the development of this research is known as the case study. The case study method, applied to Social Sciences, is a research strategy that focuses on understanding the dynamics that occur in particular scenarios. These studies use different sources and methods of collecting data (files, questionnaires, interviews and observations). The data so obtained can be quantitative, qualitative or both. The purpose of the case study is varied: to provide a description, verify an existing theory or generate a theory [20].

The criteria for the selection of cases are varied and it is essential to be fully aware of what kind of case we are considering. This allows us to know the contribution that this study will make to our knowledge.

To do this we must reflect on the status of the case that has been selected for study in relation to the universe of cases to which it belongs. For the case we have chosen, we have a central one, which is one that occurs when a phenomenon has been barely, or not at all studied previously and it is usually the best choice to focus on cases, which are central, or are very important, to the universe considered. Case studies include organizations, processes or programs, among others. This type of study is adopted as a research strategy when: a) the question revolves around how and why; b) the researcher has little control over events and c) the focus is on a contemporary phenomenon in a real life context [23].

These three circumstances are found in our investigation, as the collaborative economy is relatively recent [1], the questions revolve around how and why, and our research will help us to understand the reasons for the rapid rise of 
this economic model and its causes. It is therefore an empirical inquiry that investigates a contemporary phenomenon in a real life context and where multiple sources of evidence are used [69].

The chosen method is an indispensable tool in many areas where current issues are analyzed, such as the adoption and use of technology, and gives researchers an opportunity to acquaint themselves with new concepts by applying them to a specific case. To do this, a research strategy has been developed which is directed towards understanding the dynamics present in unique contexts and combines different methods for improving the quality in the collection of qualitative and/or quantitative samples in order to verify and generate theories [38].

\subsection{The Case of Airbnb}

The origin of Airbnb is based on the idea of Joe Gebbia and Brian Chesky, residents in San Francisco. They attended a Design Congress in San Francisco and in the absence of any available hotel rooms in the city, they decided to rent out their home. In this way, they generated some income. Thus emerged the idea of starting a business with travelers who needed a place to stay and people who wanted to rent out their extra space, and then later they commissioned the programming of a booking website [13].

Airbnb.com was founded in 2008 and in 2015 had more than 25 million visitors, a presence in more than 34,000 cities in over 190 countries and more than one million rooms worldwide [43]

In 2014, it had a gross turnover of 423 million dollars in bookings and at the end of 2015, this figure could reach 675 billion dollars. For users, the choice of Airbnb, as a way to select the stay on a trip, has a lot to do with trust and familiarity [44]. These two factors are in turn related to the results of Internet searches. Internet searches enhance user confidence and familiarity with this collaborative economy service.

\subsection{Hypothesis}

To demonstrate from a quantitative point of view the influence of search term statistics referring to collaborative economy services with Internet search engines, we have established a working hypothesis. The objective of this hypothesis is to test whether the demand for information, or searches in search engines, Google Trends about this service has a positive influence on the final volume of collaborative economy services, which are contracted measured in economic terms (Revenue in $€$ ). We will focus on the keyword Airbnb and establish that Internet searches for this keyword have a positive influence on the total spending of those tourists who booked apartments in Spain during the last year. In this way, the working hypothesis to be tested will focus on the explanatory power of the revenue figure, measured in total spending by tourists who book tourist apartments in Spain.

This treatment of the data in short time spans, has been applied in different studies [3] [2], [59], as an alternative method that took into account the serial dependence, and did not require a large number of observations. The aim is to transform the original observations to correct the autocorrelation between the residuals, so that once the data is processed, we can estimate how it influences the intervention [40]-[41] using the standard OLS (ordinary least squares) and alternatively, to confirm the model, by focusing on WLS (weighted least squares).

Applying these considerations to the study we assume that the greater the interest in collaborative economy, the greater the requests made to the Internet search engines for related terms, in this case with Airbnb.

The empirical test of the hypothesis would be as follows:

\section{Hi: Internet searches have a positive influence on the total spending by tourists who book holiday apartments.}

From a quantitative point of view, it seems obvious that the search volume (GT) will not be the only independent variable in the model. Thus, the other variable found is the supply, measured, in this case, by the number of tourist Apartments available (A). The dependent variable was thus Income (I), measured in monetary terms, of the tourists who booked apartments. To quantify this relationship, we propose the following econometric panel data model:

$$
\mathrm{I}=\beta 1+\beta 2 \mathrm{~A}+\delta \mathrm{GT}+\mathrm{u}
$$

$\mathrm{I}$ : is Income (I), measured in monetary terms, from the tourists who booked apartments in Spain.

A: is the number of tourist apartments available in Spain in 2015/16.

GT: is the number of searches in Spain for the selected keyword.

If the $\beta 1$ parameter measures the relationship between searches for the term Airbnb on the Internet, and the revenues measured as the sum of expenditures of tourists in tourist apartments in each country is statistically significant and positive, we understand that Internet searches provide relevant information when explaining the earnings from the collaborative economy in Spain. 
To carry out the estimates proposed by the OLS (Ordinary Least Squares) Model and the weighted least squares, we used the econometric software GRETL. This choice was because it is frequently used, as it is free-distribution software, because of its graphical interface and its ability to interact with R-project.

\subsection{Data and Sample}

Unlike the analyses explained above, which have been carried out with Google tools, statistics to check this hypothesis have been obtained using the KWFinder tool. This tool provides monthly search volumes of any keyword in all browsers, giving more precise information, and has enabled us to segment the analysis into searches done from Spain and search engines with Spanish domains (.es). We must also remember that the data provided by Google are averages. Therefore, the use of KWFinder is caused by this restriction on the results that Google has applied to the results obtained from Google AdWords with the Keyword Planner tool. With this tool, we can only achieve approximations as results and not real search volume data.

The data obtained were monthly time series from July 2015 to August 2016 and are considered as part of the time series data for the independent variable (GT).

The actual data come from Spanish and Portuguese public organizations that have official statistics of occupation of tourist apartments throughout the country, did not take into account regional data and we do not have data by cities. Moreover, the INE (National Statistics Institute) of the Spanish Government publishes a monthly study on tourist apartments: survey of occupation and price index. The aim is to provide information on the supply and demand of accommodation services establishments providing tourist apartments [29]. The variables studied are travelers, overnight stays, average stay and occupancy rate for place of residence, month, type of accommodation, category, location, and personnel employed in category, type of contract and month. We therefore selected Spain, given the potential for tourism of the country and its relevance and tradition for this type of study.

\section{Results}

The data delivered by Google are weekly search statistics. The representation of the data is weekly and includes the results from Sunday to the next Saturday. The periods are standardized equally for all terms and cover the period between August 2006 and the same month in 2016. In this period, we have 121 monthly observations.

The representativeness of the sample is based on the fact that the periods are the same size and hence searches may be related, as they have been made under the same economic conditions. The statistics for Google searches have been downloaded directly from the Google Trends page, in the periodic search statistics section.

\subsection{Regions and Cities that Show Most Interest in Airbnb Service}

Figure 1 shows the map of search density for Airbnb in Portuguese and Spanish cities. In the case of the regions of each country, we present the ranking of the data of those that have the best search data. Those with the highest and lowest indices in the given ranking are shown.

As can be seen in Figure 1, the term Airbnb is consulted primarily in Palma de Mallorca, Barcelona, Seville, Bilbao, Valencia, Malaga and Madrid. The ranking of Madrid in the list is surprising, as is the high position of Sevilla in the search order. By region, Balearic Islands, Basque Country, Ceuta, Catalonia and Navarra are the regions where most searches are made. At the end of the rankings are Madrid, Murcia and Castilla-La Mancha. In the case of Portugal, searches are centralized in Lisbon, although the districts of Faro and Beja represent the largest percentage of searches, with Viseu and Setubal the regions with the lowest. 


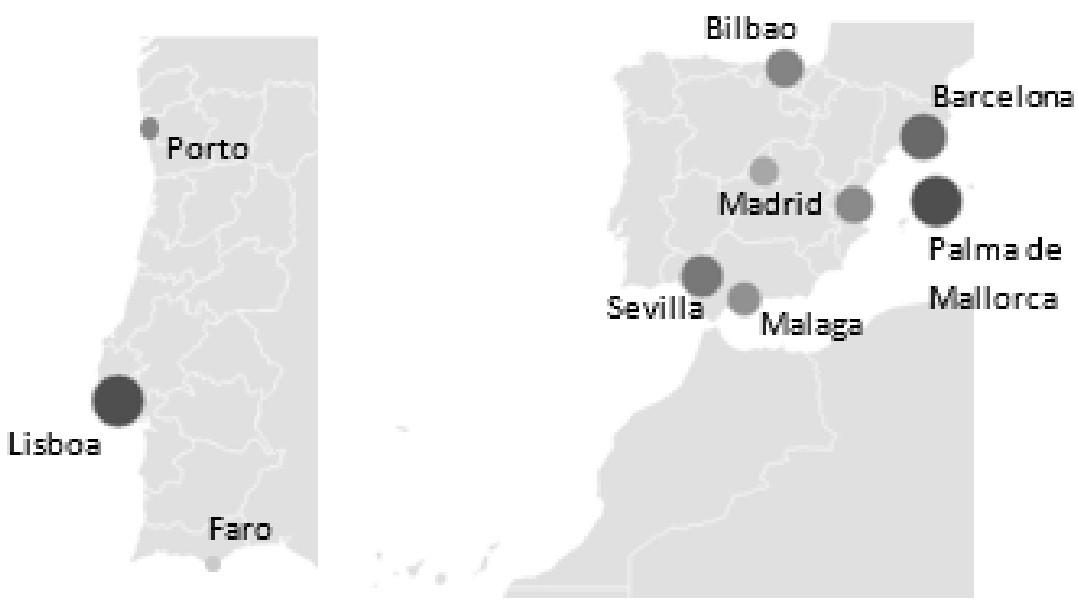

Figure 1: Map of search density for Airbnb in Portuguese and Spanish cities

\subsection{Interest in the Collaborative Economy in Spain and Portugal with Respect to the Country of Origin of Airbnb}

In first place, we have analyzed the interest that exists, through the searches, by Airbnb in the three countries. The numbers reflect the search interest relative to the highest value of a chart in each country and in the last 10 years. The data presented in Figure 2 show that interest in the search is similar in all three countries.

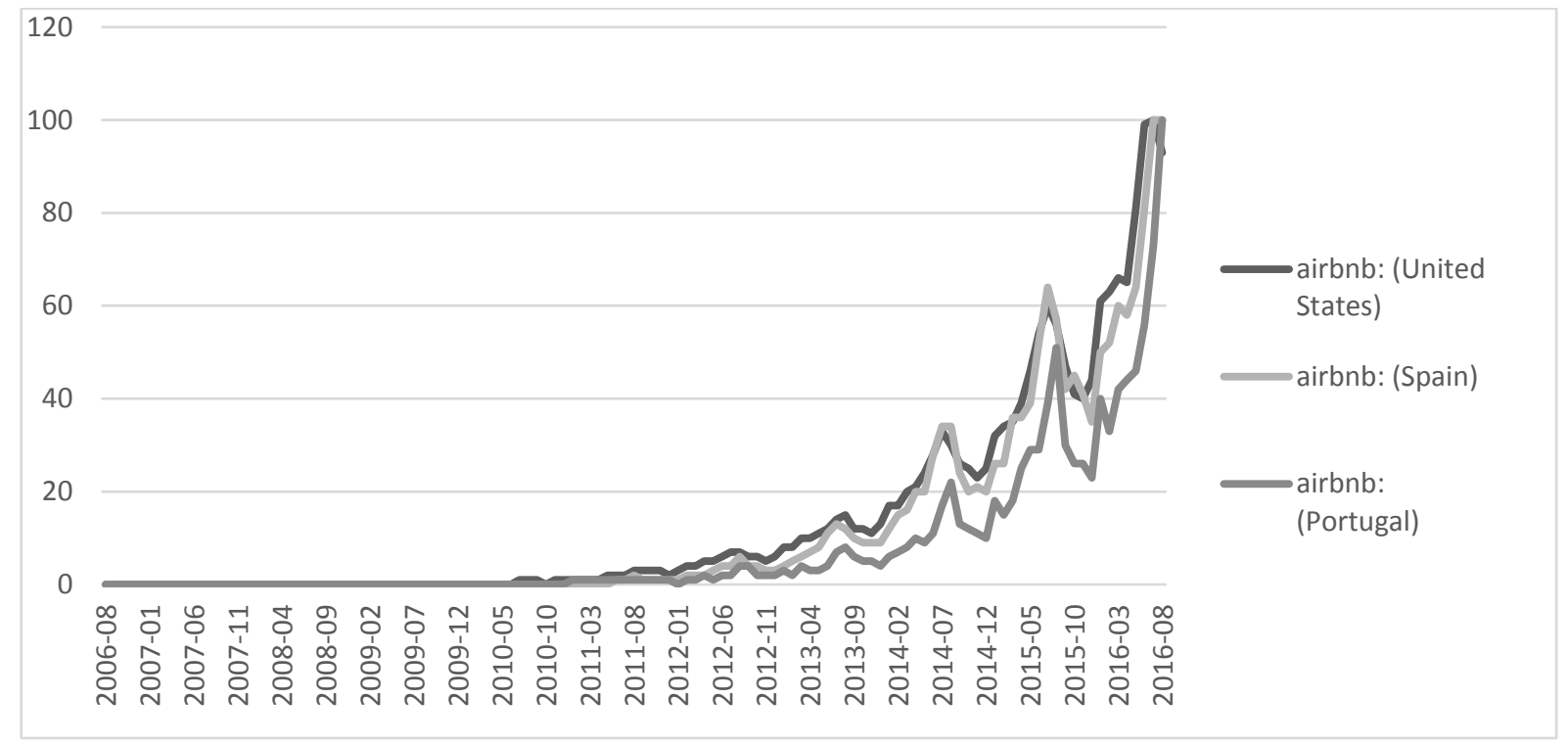

Figure 2: Geographical interest of the term Airbnb

It is noteworthy that there is greater interest in the search in the thematic area of Hobbies and free time for the case of Spain than the United States and Portugal. Figure 2 shows the trend of the three countries for the field Travel. You can clearly distinguish how seasonality affects searches, as it is a temporary hosting service. Thus, in the summer months the search for the term Airbnb increases significantly. The curves represented in the country graph have quite a few similarities among the three represented.

\subsection{Comparison of Searches for Airbnb with other Websites such as TripAdvisor, Trivago or Booking}

The third objective of the study was to show the interest in the search term Airbnb compared to others, which do not 
belong to the model of the collaborative economy, but are current alternatives in some cases or direct competitors in others.

For this purpose, we looked for the three search terms related to the main webs of tourist infomediation for destinations and accommodation in Spain. Using the KWFinder tool, it was found that TripAdvisor, Booking and Trivago were the most consulted (see Figure 3).

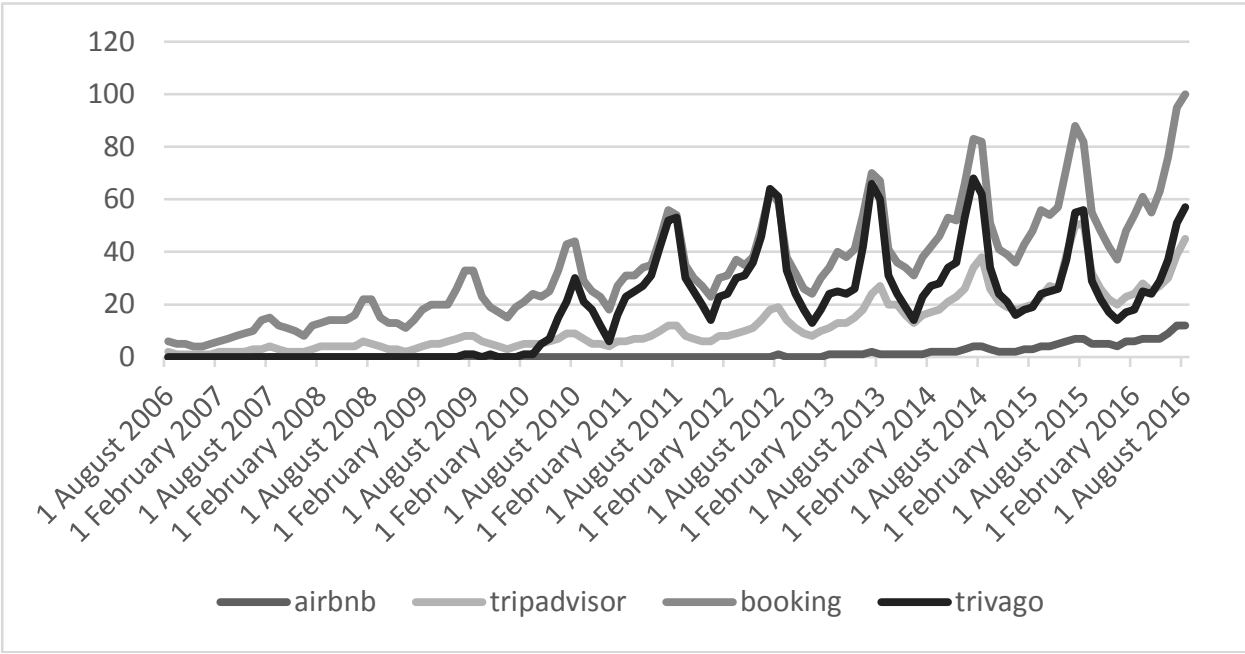

Figure 3: Comparison of searches for Airbnb service with other websites for Spain

Another outstanding difference is that, in the case of the search data for Spain, Booking leads the ranking, followed by Trivago and TripAdvisor.

\subsection{Relationship between the Rise in Popularity of Internet Access, the Use of Social Networks and Airbnb}

In Table 2, it is possible to see the results of the regression of search terms with the highest degree of correlation. All the search statistics in Google have been significant (and therefore are assumed to explain the evolution of the collaborative economy), although they are different depending on whether the representative search term was Airbnb.

Our main interpretations of the parameters obtained focus on demonstrating the direct correlation between the search term Airbnb and those shown in the second and third columns. As can be seen in both tables, from all the terms that have a closer correlation than $r=1$, there are several related to the increased use of Internet in homes and the providers (Ono customer area, Myorange, Jazztel fibre and Movistar fibre). Especially now with the use of fiber optics and Internet access through $4 \mathrm{G}$ mobile networks. The selected terms have values close to $1(0.9588,0.9686)$ and show a direct relationship.

Table 2: Correlation combined with the term Airbnb

\begin{tabular}{|l|l|l|l|}
\hline $\begin{array}{l}\text { Collaborative } \\
\text { Economy }\end{array}$ & Internet use & Social Networks & $r$ \\
\hline \multirow{4}{*}{} & Ono clients area & & \\
\cline { 2 - 4 } & & & 0.9588 \\
\cline { 2 - 4 } & & Snapchats & 0.9698 \\
\cline { 2 - 4 } & & Youtubers & 0.9580 \\
\cline { 2 - 4 } & My orange & & 0.9574 \\
\hline
\end{tabular}

The search term has a high correlation with the term studied, Snapchats and Youtubers, which are the social networks that appears in Google Insights for Search. The selected terms have values very close to 1 (0.9580 and 0.9574). The terms selected are related to social networks and chat services. This high correlation can demonstrate that the existence of this service is closely related to the rise and consolidation of social networks.

\subsection{Results of the Testing of the Proposed Hypothesis}

The results show that the estimated parameter with the sample used is significantly different from zero $\left(R^{2}=86.12 \%\right)$ if we use combined OLS and even higher if the regression is conducted using generalized least squares $(G L S)\left(R^{2}=\right.$ $88.83 \%)$ [67]. 
Tables 3 and 4 show the parameters obtained from the various regressions compiled with software Gretl.

The results confirm the hypothesis presented in this paper. Therefore, we can confirm that Hi: Internet searches have a positive influence on the total spending by tourists who book holiday apartments.

Table 3: Model 1 OLS

\begin{tabular}{|l|l|l|l|l|l|}
\hline & Coefficient & S. D & $z$ & $p$ value & \\
\hline Const & 928.376 & 108814 & 0.0085 & 0.9932 & \\
\hline GT & 0.493569 & 0.0473201 & $\begin{array}{l}10.430 \\
4\end{array}$ & $<0.0001$ & \\
\hline Accom. & 1.21745 & 0.223714 & 5.4420 & $<0.0001$ & \\
\hline Dep. vble. ave & 1095453 & & Dep. Vble. S.D. & 276495.5 \\
\hline Sum sqrd. residuals & $1.17 \mathrm{e}+11$ & & S.D. regression & 113892.1 \\
\hline R-squared & 0.861177 & & R-squared corrected & 0.830328 \\
\hline F(2, 9) & 106.7189 & & p value (of F) & $5.39 \mathrm{e}-07$ \\
\hline Log-verisimilitude & -155.0173 & & Akaike criterion & 316.0345 \\
\hline Schwarz criterion & 317.4892 & & Hannan-Quinn crit. & 315.4959 \\
\hline Rho & -0.501690 & & Durbin-Watson & 2.934860 \\
\hline
\end{tabular}

Table 4: Model 2 WLS

\begin{tabular}{|c|c|c|c|c|c|c|}
\hline & \multicolumn{2}{|c|}{ Coefficient } & S. D & z & $p$ value & \\
\hline Const & \multicolumn{2}{|c|}{30565} & 108142 & 0.2826 & 0.7775 & \\
\hline GT & \multicolumn{2}{|c|}{0.482939} & 0.0439894 & 10.9785 & $<0.0001$ & 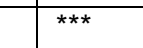 \\
\hline Accom. & \multicolumn{2}{|c|}{1.18207} & 0.238107 & 4.9644 & $<0.0001$ & *** \\
\hline \multicolumn{2}{|l|}{ Sum sqrd. residuals } & \multicolumn{2}{|l|}{$1.16 e+17$} & \multicolumn{2}{|l|}{ S.D. regression } & $1.13 e+08$ \\
\hline \multicolumn{2}{|l|}{ R-squared } & \multicolumn{2}{|l|}{0.888325} & \multicolumn{2}{|l|}{ R-squared corrected } & 0.863508 \\
\hline \multicolumn{2}{|l|}{$\mathrm{F}(2,9)$} & \multicolumn{2}{|l|}{35.79549} & \multicolumn{2}{|l|}{$\mathrm{p}$ value (of $\mathrm{F}$ ) } & 0.000052 \\
\hline \multicolumn{2}{|l|}{ Log-verisimilitude } & \multicolumn{2}{|l|}{-237.8564} & \multicolumn{2}{|l|}{ Akaike criterion } & 481.7127 \\
\hline \multicolumn{2}{|l|}{ Schwarz criterion } & \multicolumn{2}{|l|}{483.1675} & \multicolumn{2}{|l|}{ Hannan-Quinn crit. } & 481.1741 \\
\hline \multicolumn{2}{|l|}{ rho } & \multicolumn{2}{|l|}{-0.493618} & \multicolumn{2}{|l|}{ Durbin-Watson } & 2.940234 \\
\hline \multicolumn{2}{|l|}{ Dep. vble. ave } & \multicolumn{2}{|l|}{1095453} & \multicolumn{2}{|l|}{ Dep. Vble. S.D. } & 276495.5 \\
\hline Sum sqrd. residuals & & $1.17 e+11$ & & S.D. regression & & 114115.0 \\
\hline
\end{tabular}

\section{Conclusion}

Over the last two decades, the development of the Internet has meant that there has been an increase in the number of Internet users and web services that are provided on the network. One of the fastest growing services has been search engines. The growth of the Internet has made it difficult to rank the services it provides and these search engines have played an essential role in positioning and locating information and services. The collaborative economy, as we now know it, started thanks to the development of web services, as these provide the means for collaboration between individuals. Therefore, we can conclude that the collaborative economy is part of the digital economy and its development is increasing year after year, in the light of the data found and shown in this article. Nowadays, there are brands or companies providing popular services. We can say that Airbnb, which was the case studied, is very representative of this economic model, even though there is a large number of lesser-known websites.

We used the tools provided by Google to analyze trends based on search terms. The correlations between searched words can be considered a quantitative method of observation, valid for the study of the demand for information and consequently future demands for web service, in our case of the collaborative economy. 
The service studied is experiencing considerable progress in terms of search requests. These searches in Spain and Portugal are very evenly matched to the patterns in it country of origin. Areas where increased demands for these terms exist in the Google search engine, do not always match those areas with larger populations. In the case of Airbnb, they coincide with the areas of greatest tourist attraction. Compared with other touristic travel or accommodation websites, it follows a seasonal pattern coinciding with the demand, although it does it less sharply.

The results found support to previous studies that defend that tools for studying trends [21] and correlations of search terms are techniques that help decision making in studies and market research. Fundamentally, they constitute a potential source for the observation of the preferences and interests of consumers, which can provide highly valuable information when developing marketing policies. We have highlighted the existence of highly significant correlations with terms related to social networks and the use of technologies as well as Internet access providers.

Once an econometric model statistics panel has been made for the searches, a keyword related to collaborative economy in the tourism sector, we could demonstrate its explanatory power for income from tourist apartments. The results are significant in $86.12 \%$, if we use combined OLS and even higher if the regression is conducted using WLS, reaching $88.83 \%$. Therefore, Internet searches for collaborative economy services (as in the case of Airbnb) influence the contribution to the GDP (Gross Domestic Product) of the Spanish tourism sector.

The results can help executives and managers of collaborative economy services to predict trends in the rental market of tourist apartments, have a tool that can estimate the evolution of short-term demand and the preferences of consumers based on their searches as users of Internet search engines. Indeed, this study confirms the importance of increasing investment in SEO (Search Engine Optimization) and SEM (Search Engine Marketing) positioning.

In the field of economics, we have found varied studies, such as those that predict economic indicators: car sales, unemployment or tourist destinations [16], applied economics [16] [53], human resources [7], [18], price evolution [27], consumption [28], [37] [52], [54] [58] and digital economy [33].

Finally, the results are limited to Spain and Portugal, as well as to the USA, the country of origin of Airbnb. Therefore, we suggest that future work has to extend the scope and reach of the study. Similarly, these studies are exploratory in nature and can help us to determine the factors and variables that will condition the future development of the collaborative economy.

\section{References}

[1] R. Algar. (2007, April) Collaborative consumption. Internet Archive, Wayback Machine. [Online]. Available: http://web.archive.org/web/20130514173126/http://www.oxygen-consulting.co.uk/docs/collaborative-consump$\underline{\text { tion.pdf }}$

[2] J. Algina and H. A. Swaminathan, A procedure for the analysis of time-series designs, Journal of Experimental Education, vol. 4, no. 5, pp. 56-61, 1977.

[3] J. Algina and H. A. Swaminathan, Alternatives to Simonton's analyses of the interrupted and multiple-group timeseries designs, Psychological Bulletin, vol. 86, pp. 919-926, 1979.

[4] C. Anderson, The New Industrial Revolution. New York: Crown Business, 2012.

[5] B. H. Archer, Demand forecasting and estimation, in Travel, Tourism, and Hospitality Research (J. R. B. Ritchie and C. R. Goeldner, Eds.). New York, NY: Wiley, 1987, pp. 77-85.

[6] C. Artola, F. Pinto and P. De Pedraza García, Can internet searches forecast tourism inflows? International Journal of Manpower, vol. 36, no. 1, pp. 103-116, 2015.

[7] N. Askitas and K. F. Zimmermann. (2009, April) Google econometrics and unemployment forecasting. Dunker \& Humblot eJournals. [Online]. Available: http://ejournals.duncker-humblot.de/doi/abs/10.3790/aeq.55.2.107

[8] S. Aznal. (2014, July) Las nuevas actitudes hacia el consumo y la producción: Las mejores prácticas en el ámbito del consumo colaborativo y la obsolescencia planificada. Economía Solidaria. [Online]. Available: http://www.economiasolidaria.org/files/estudio\%20v.f.pdf

[9] P. F. Bangwayo-Skeete and R. W. Skeete, Can Google data improve the forecasting performance of tourist arrivals? Mixed-data sampling approach, Tourism Management, vol. 46, pp. 454-464, 2015.

[10] S. J. Barnes and J. Mattsson, Understanding current and future issues in collaborative consumption: A four-stage Delphi study, Technological Forecasting and Social Change, vol. 104, pp. 200-211, 2016.

[11] V. R. Basili, The experience factory and its relationship to other quality approaches, Advances in Computers, vol. 41, pp. 65-82, 1995.

[12] M. Bauwens, N. Mendoza and F. lacomella. (2012) Synthetic overview of the collaborative economy. P2PF Wiki. [Online]. Available: http://wiki.p2pfoundation.net/Synthetic Overview of the Collaborative Economy

[13] R. Botsman and R. Rogers, What's Mine is Yours: The Rise of Collaborative Consumption. New York: Harper Collins e-books, 2010.

[14] R. Buyya, C. Yeo, S. Venugopa, J. Broberg, and I. Brandic, Cloud computing and emerging it platforms: Vision, hype, and reality for delivering computing as the 5th utility, Future Generation Computer Systems, vol. 25, no. 6, pp. 599-616, 2009.

[15] A. Cañigueral, Consumo compartido, un nuevo tipo de negocio que juega al alza, Harvard Deusto Marketing y Ventas, vol. 121, pp. 40-49, 2014. 
[16] H. Choi and H. Varian, Predicting initial claims for unemployment insurance using Google Trends. Google Inc., pp. 1-5, 2009.

[17] H. Choi and H. Varian, Predicting the present with Google Trends, Economic Record, vol. 88s1, pp. 2-9, 2012.

[18] F. D'Amuri and J. Marcucci. (2010, April) Google it! Forecasting the US unemployment rate with a Google job search index. Social Science Research Network, 2010. [Online]. Available: http://papers.ssrn.com/sol3/papers. cfm?abstract id=1594132

[19] R. Díaz Armas, D. Gutiérrez Taño and F. García-Rodríguez. ¿Por qué Airbnb es un modelo de alojamiento colaborativo con tanto exito? En J. A. Mondéjar Jiménez y E. Parra López (Eds.), La actividad turistica española en 2014. Vallehermoso, Madrid: SINTESIS, 2015, pp. 111-119.

[20] S. Diez-Toribio. (2015, July) La economía colaborativa: Un nuevo modelo de consumo que requiere la atención de la política económica. Universidad de Valladolid. [Online]. Available: http://uvadoc.uva.es/bitstream/ 10324/15665/1/TFG-E-141.pdf

[21] G. Dinis, C. Costa and O. Pacheco, Nós Googlamos! Utilização da ferramenta Google Trends para compreender o interesse do público pelo Turismo no Algarve, Dos Algarves: A Multidisciplinary e-Journal, vol. 261, pp. 64-84, 2015

[22] K. Eisenhardt, Building theories from case study research, The Academy of Management Review, vol. 14, no. 4, pp. 532-550, 1989.

[23] P. Forni, Los estudios de caso: Orígenes, cuestiones de diseño y sus aportes a la teoría social, Miríada: Investigación en Ciencias Sociales, vol. 3, no. 5, pp. 61-80, 2010.

[24] R. Fernández-Reyes, J. L. Piñuel-Raigada and M. Vicente-Mariño, La cobertura periodística del cambio climático y del calentamiento global en el país, el mundo y la vanguardia, Revista Latina de Comunicación Social, vol. 70 , no. 2, pp. 122-140, 2015.

[25] R. Gómez and C. Prado, Sentimiento del inversor, selección española de fútbol y su influencia sobre el Ibex 35, in Proceedings XXI Congreso Internacional AEDEM, Bucarest, 2012.

[26] Google. (2015) Google Trends. Interés a lo largo del tiempo. Google. [Online]. Available: https://support.google.com/trends/?hl=es\#topic=6248052

[27] G. Guzmán, Internet search behavior as an economic forecasting tool: The case of inflation expectations, The Journal of Economic and Social Measurement, vol. 36, no. 3, pp. 119-167, 2011.

[28] H. Huang and N. D. Penna, Constructing consumer sentiment index for U.S. using Google searches, University of Alberta, Edmonton, Canada, Working Paper 2009-26, 2009.

[29] INE-Instituto Nacional de Estadística. Ministerio de economía y competitividad. Secretaría de Estado de Economía y Apoyo a la Empresa del Gobierno de España. 2016. [Online]. Available: http://www.ine.es/dyngs/INEbase/es/operacion.htm?c=Estadistica C\&cid=1254736176962\&menu=ultiDatos\&id $\mathrm{p}=1254735576863$

[30] M. Jackman and S. Naitram, Research note: Nowcasting tourist arrivals in Barbados-just Google it!, Tourism Economics, vol. 216, pp. 1309-1313, 2015.

[31] J. Jeng and D. R. Fesenmaier, Conceptualizing the travel decision-making hierarchy: A review of recent developments, Tourism Analysis, vol. 7, no. 1, pp. 15-32, 2002.

[32] L. Kristoufek, BitCoin meets google trends and wikipedia: Quantifying the relationship between phenomena of the Internet era, Scientific Reports, vol. 3, no. 3415, 2013.

[33] L. Kristoufek, Can Google Trends search queries contribute to risk diversification?, Scientific Reports, vol. 3, p. 2713,2013

[34] M. Lemmon and E. Portniaguina, Consumer confidence and asset prices: Some empirical evidence, The Review of Financial Studies, vol. 19, no. 4, pp. 1499-1529, 2006

[35] G. Li, K. K. Wong, H. Song, and S. F. Witt, Tourism demand forecasting: A time varying parameter error correction model, Journal of Travel Research, vol. 45, no. 2, pp. 175-185, 2006.

[36] V. S. Lin, A. Liu and H. Song, Modeling and forecasting Chinese outbound tourism: An econometric approach, Journal of Travel \& Tourism Marketing, vol. 32, no. 1-2, pp. 34-49, 2015.

[37] F. Lindberg, Nowcasting Swedish retail sales with google search query data, M.S. thesis, Stockholm University, Sweden, 2011.

[38] P. Martínez Carazo, El método de estudio de caso: Estrategia metodológica de la investigación científica, Pensamiento \& Gestión, vol. 20, pp. 163-193, 2006.

[39] R. G. Martínez, Señales de inversión basadas en un índice de aversión al riesgo, Investigaciones Europeas de Dirección y Economía de la Empresa, vol. 193, pp. 147-157, 2013.

[40] R. G. Martínez, M. P. Román and C. M. Idoeta, Google search activity as entrepreneurship thermometer, in New Challenges in Entrepreneurship and Finance (M. Peris-Ortiz and J.M. Sahut, Eds.). Heidelberg: Springer International Publishing, 2015, pp. 225-233.

[41] R. G. Martínez, P. P. Casado, C. P. Román, and M. P. Román, Google Trends como indicador válido para los ingresos por la producción de vino, Tourism and Hospitality International Journal, vol. 62, pp. 94-106, 2016.

[42] Y. Matias. (2013, September) Insights into what the world is searching for the new Google Trends, insights Search, the official google search blog. Google. [Online]. Available: https://search.googleblog.com/2012/09/insights-intowhat-world-is-searching.html

[43] B. Mendes Izard. (2015, June) Generación de confianza en el mundo real a través de interacciones en el mundo virtual en el contexto de la economía colaborativa: el caso de AIRBNB: Un enfoque en su sistema de evaluación entre iguales. Universidad de Comillas. [Online]. Available: https://repositorio.comillas.edu/xmlui/bitstream/ handle/11531/4585/TFG001361.pdf?sequence=1 
[44] M. Möhlmann, Collaborative consumption: Determinants of satisfaction and the likelihood of using a sharing economy option again, Journal of Consumer Behaviour, vol. 14, no. 3, pp. 193-207, 2015.

[45] T. Oliveira, M. Thomas and M. Espadanal, Assessing the determinants of cloud computing adoption: An analysis of the manufacturing and services sectors, Information \& Management, vol. 51, pp. 497- 510, 2014.

[46] I. Önder and U. Gunter, Forecasting tourism demand with Google Trends for a major European city destination, Tourism Analysis, vol. 212, no. 3, pp. 203-220, 2016.

[47] J. Owyang, C. Tran and C. Silva, The Collaborative Economy. United States: Altimeter, 2013.

[48] P. R. Palos and M. B. Correia, La actitud de los recursos humanos de las organizaciones ante la complejidad de las aplicaciones SaaS, Dos Algarves: A Multidisciplinary e-Journal, vol. 28, pp. 87-103, 2016.

[49] P. R. Palos and M. B. Correia, The paradigm of the cloud and web accessibility and its consequences in Europe, in Proceedings 7th International Conference on Software Development and Technologies for Enhancing Accessibility and Fighting Info-exclusion DSAI, Communications of ACM, Vila Real, Portugal, 2016.

[50] P. R. Palos-Sanchez, F. J. Arenas-Marquez and M. Aguayo-Camacho, Cloud computing (SaaS) adoption as a strategic technology: Results of an empirical study, Mobile Information Systems, vol. 1, pp. 1-20, 2017.

[51] S. Park, J. Lee and W. Song, Short-term forecasting of Japanese tourist inflow to South Korea using google trends data, Journal of Travel \& Tourism Marketing, vol. 34, no. 3, pp. 357-368, 2017.

[52] T. Preis, D. Reith and H. Eugene Stanley, Complex dynamics of our economic life on different scales: Insights from search engine query data, Philosophical Transactions of the Royal Society of London, vol. 368, pp. 57075719,2010 .

[53] T. Preis, H. S. Moat and H. E. Stanley, Quantifying trading behavior in financial markets using Google Trends, Scientific reports, vol. 3, p. srep01684, 2013.

[54] J. Prieto-Gutiérrez, Herramientas para el análisis y monitoreo en redes sociales, International Review of Information Ethics, vol. 16, pp. 33-40, 2011.

[55] K. Radinsky, S. Davidovich and S. Markovitch, Predicting the news of tomorrow using patterns in web search queries, in Proceedings of the 2008 IEEE/WIC/ACM International Conference on Web Intelligence WI08, Washington, DC, 2009, pp.363-367

[56] V. Ratten, Continuance use intention of cloud computing: Innovativeness and creativity perspectives, Journal of Business Research, vol. 69, no. 5, pp. 1737-1740, 2016.

[57] R. Rivera, A dynamic linear model to forecast hotel registrations in Puerto Rico using google trends data, Tourism Management, vol. 57, pp. 12-20, 2016.

[58] T. Schmidt and S. Vosen, Forecasting private consumption: Survey-based indicators vs. Google Trends', Journal of Forecasting, vol. 30, no. 6, pp. 565-578, 2011.

[59] D. K. Simonton, Creative productivity, age, and stress: A biographical time-series analysis of 10 classical composers, Journal of Personality and Social Psychology, vol. 35, no. 11, 791-804, 1977.

[60] D. Tapscott and M. B. Osorio, La Economía Digital. New York: McGraw-Hill, 1997.

[61] A. Toffler and A. Martín, La Tercera Ola / The Third Wave (No. 316.42). Bogotá: Plaza \& Janes, 1980.

[62] V. F. Ukolov, A. V. Solomatin, Y. V. Solomatin, S. U. Chernikov, and A. V. Ukolov, Food-sharing economy pattern comparison in UK and Russian markets, International Business Management, vol. 10, no. 18, pp. 4268-4282, 2016.

[63] C. Valor, Economía en colaboración, Economistas sin Fronteras, vol. 12, pp. 4, 2014.

[64] L. Vaughan, Discovering business information from search engine query data, Online Information Review, vol. 384, pp. 562-574, 2014.

[65] L. Vaughan and Y. Chen, Data mining from web search queries: A comparison of google trends and baidu index, Journal of the Association for Information Science and Technology, vol. 661, pp. 13-22, 2015.

[66] S. Vosen and T. Schmidt, Forecasting private consumption: Survey-based indicators vs. google trends, Journal of Forecasting, vol. 306, pp. 565-578, 2011.

[67] J. M. Wooldridge, Econometric Analysis of Cross Section and Panel Data. Cambridge, Massachusetts: Institute of Technology University Press, 2010.

[68] X. Yang, B. Pan, J. A. Evans, and B. Lv, Forecasting Chinese tourist volume with search engine data. Tourism Management, vol. 46, pp. 386-397, 2015.

[69] R. Yin, Case Study Research. Design and Methods. Thousand Oaks, Ca: Sage Publications, 1984.

[70] J. J. Zhu, X. Wang, J. Qin, and L. Wu, Assessing public opinion trends based on user search queries: Validity, reliability, and practicality, in Proceedings The Annual Conference of the World Association for Public Opinion Research, Hong Kong, 2012, pp. 1-7 